\title{
Brachydactyly-short stature-retinitis pigmentosa syndrome
}

INSERM

\section{Source}

INSERM. (1999). Orphanet: an online rare disease and orphan drug data base.

Brachydactyly-short stature-retinitis pigmentosa syndrome. ORPHA:166035

Brachydactyly-short stature-retinitis pigmentosa syndrome is a rare, genetic, congenital limb malformation syndrome characterized by mild to severe short stature, brachydactyly, and retinal degeneration (usually retinitis pigmentosa), associated with variable intellectual disability, develomental delays, and craniofacial anomalies. 